\title{
INTEGRASI TOKO ONLINE MENGGUNAKAN TEKNOLOGI WEBSERVICE
}

\author{
Budi Santosa, Dessyanto Boedi Prasetyo,Yunita Pungki \\ Jurusan Teknik Informatika Fakultas Teknologi Industri \\ Universitas Pembangunan Nasional "Veteran" Yogyakarta \\ Jl. Babarsari No.2 Yogyakarta 55281 \\ email: dissan@if.upnyk.ac.id
}

\begin{abstract}
Currently there are many online stores to facilitate sellers to promote their products as well as expand the scope of its work. Online store (webstore) or web e-commerce sales transactions emphasizing that can take place in real time from anywhere as long as it is connected to the net and service orientation to customer / community as its focus. Amazon, Ebay, and Commission Junction is an example webstore. As a burgeoning webstore, they provide many products, ranging from electronic goods, clothing, automotive, jewelry, to books.

Sometimes a little trouble if the buyer must access their pages one by one. To that made a sales application designed using webservice technology in order to reduce the problem of data integration from multiple sales sites (Amazon, Commission Junction, and Ebay) so prospective buyers can easily compare various products and prices offered in a market segment. This online sales application created using the PHP programming language and MYSQL as the database with data collection methods used in this application is the study of literature and methodology for system development using Waterfall.

Resulting software could help the process of integrating data from multiple sales sites (Amazon, Commission Junction, and Ebay). The software also handles the process of adding, changing, and deletion of data products that have been stored in the database. This software is used by 2 users ie visitors / buyers and admin.
\end{abstract}

\section{Keywords : E-commerce, Webservice, PHP}

Saat ini banyak terdapat toko online untuk memudahkan penjual mempromosikan produk-produknya sekaligus memperluas ruang lingkup kerjanya. Toko online (webstore) atau web e-commerce menekankan kepada transaksi penjualan yang dapat berlangsung secara real time dari mana saja asalkan terhubung dalam jaringan internet dan orientasi pelayanan kepada customer/masyarakat sebagai fokusnya. Amazon, Ebay, dan Commission Junction merupakan contoh webstore. Sebagai webstore yang sedang berkembang, mereka menyediakan banyak produk, mulai dari barang elektronik, pakaian, otomotif, perhiasan, hingga buku.

Kadang pembeli agak repot jika harus mengakses halaman mereka satu persatu. Untuk itu dibuatlah suatu aplikasi penjualan yang dirancang dengan menggunakan teknologi webservice agar dapat mengurangi masalah integrasi data dari beberapa situs penjualan (Amazon, Commission Junction, dan Ebay) sehingga calon pembeli dapat dengan mudah membandingkan berbagai macam produk dan harga yang ditawarkan dalam sebuah segmen pasar. Aplikasi penjualan online ini dibuat menggunakan bahasa pemrograman PHP dan MySQL sebagai database dengan metode pengumpulan data yang digunakan dalam aplikasi ini adalah studi pustaka dan untuk pengembangan sistem menggunakan metodologi Waterfall.

Perangkat lunak yang dihasilkan mampu membantu proses pengintegrasian data dari beberapa situs penjualan (Amazon, Commission Junction, dan Ebay). Perangkat lunak juga menangani proses penambahan, perubahan, dan penghapusan terhadap data produk yang telah tersimpan dalam database. Perangkat lunak ini digunakan oleh 2 user yaitu pengunjung/pembeli dan admin.

Kata Kunci : E-commerce, Webservice, PHP

\section{PENDAHULUAN}

Saat ini banyak terdapat toko online untuk memudahkan penjual mempromosikan produk-produknya sekaligus memperluas ruang lingkup kerjanya. Amazon, Ebay, dan Commission Junction merupakan contoh webstore. Sebagai webstore yang sedang 
berkembang, mereka menyediakan banyak produk, mulai dari barang elektronik, pakaian, otomotif, perhiasan, hingga buku.

Kadang pembeli agak repot jika harus mengakses halaman mereka satu persatu. Untuk itu dibuatlah suatu aplikasi penjualan yang berbasis TI dan internet (e-commerce) dengan menggunakan teknologi webservice sehingga produk yang ada pada situs penjualan ini terdiri atas beberapa produk dari webstore Amazon, Ebay, dan Commission Junction, sehingga akan mengurangi masalah integrasi data dan calon pembeli dapat dengan mudah membandingkan berbagai macam produk dan harga yang ditawarkan dalam sebuah segmen pasar.

Kerjasama antar beberapa situs penjualan ini disebut afiliasi, dimana situs penjualan ini berperan sebagai pemasar produk (affiliate marketer) akan mendapatkan keuntungan atau bayaran yang sudah ditetapkan dari pemilik produk (affiliate merchant) setelah customer membeli produk milik affiliate merchant melalui situs penjualan ini.

\section{DASAR TEORI}

\subsection{E-commerce}

Merupakan suatu set dinamis teknologi, aplikasi dan proses bisnis yang menghubungkan perusahaan, konsumen, dan komunitas melalui transaksi elektronik dan perdagangan barang, pelayanan dan informasi yang dilakukan secara elektronik (Purbo, 2000).

\subsection{Affiliate Store}

Dalam terminologi bisnis online, afiliasi mengalami sedikit penambahan makna. Afiliasi merupakan cara menghasilkan uang dengan menjual produk dari perusahaan atau lembaga pemilik produk (affiliate merchant), dengan bergabung menjadi pemasar produk (affiliate marketers), dan (hanya) dibayar setelah produk terjual (http://blog.bukatokoonline.net/apa-ituafiliasi).

\subsection{Web Service}

Tujuan dari teknologi ini adalah untuk memudahkan beberapa aplikasi atau komponennya untuk saling berhubungan dengan aplikasi lain dalam sebuah organisasi maupun di luar organisasi menggunakan standar yang tidak terikat platform (platform-neutral) dan tidak terikat akan bahasa pemrograman yang digunakan (language-netral). Selain itu, penggunaan SOAP menjadikan method-method dari object-object yang ada dalam sebuah web service dapat diakses dari aplikasi lain seperti halnya aplikasi tersebut mengakses method lokal (Lucky, 2008).

Komponen-komponen penyusun web service yaitu XML (eXtensible Markup Language), SOAP (Simple Object Access Protocol), WSDL (Web Services Description Language), dan UDDI (Universal Description, Discovery and Integration).

\subsection{Application Programming Interface (API)}

Merupakan sekumpulan perintah, fungsi, dan protokol yang dapat digunakan oleh programmer saat membangun perangkat lunak untuk sistem operasi tertentu. (http://id.wikipedia.org/wiki/Antarmuka_pemrograman_aplikasi).

\section{$2.5 \quad$ Tools Pendukung}

Sistem ini menggunakan tools pendukung berupa PHP 5.2.9-2, MySQL, phpMyAdmin, CSS, Javascript, Macromedia Dreamweaver 8.0, dan XAMPP.

\section{ANALISIS DAN PERANCANGAN}

\subsection{Rekayasa Sistem}

Berikut merupakan beberapa identifikasi sistem yang ada, yaitu:

1. Sistem sebaiknya bisa menekan biaya modal dibandingkan sistem jual beli tradisional.

2. Sistem sebaiknya dapat mengurangi jumlah pekerja dibandingkan sistem jual beli tradisional yang membutuhkan banyak pekerja, yaitu sebuah aplikasi penjualan yang dikelola oleh seorang admin.

3. Sistem sebaiknya dapat mempromosikan produk secara online, agar ruang lingkup customer semakin luas tanpa batas ruang dan waktu asal terhubung dengan internet. 


\subsection{Analisis Kebutuhan Perangkat Lunak}

Ada dua jenis kebutuhan yang diperlukan untuk menghasilkan sebuah aplikasi yang berkualitas, yaitu kebutuhan fungsional dan kebutuhan non-fungsional.

\section{Kebutuhan Fungsional}

Aplikasi ini digunakan oleh dua user yang terdiri dari pengunjung/pembeli (customer) dan admin dengan kebutuhan fungsional, diantaranya :

1. Pengunjung/pembeli (customer)

Merupakan user yang tidak login. User ini dapat melihat informasi detail dari produk yang dimuat, melakukan pencarian terhadap produk yang diinginkan, dan melihat iklan yang tersedia.

2. Admin

Merupakan user yang mempunyai otoritas paling tinggi dari pengunjung (customer). Superuser ini dimiliki oleh seorang administrator yang bertanggungjawab antara lain :

a. Mengelola pengaturan pada aplikasi

b. Melakukan login terhadap aplikasi.

c. Melakukan pengolahan data pada database seperti penambahan, perubahan, penghapusan dan penyimpanan data pada database yang telah disediakan.

\section{Kebutuhan Non-fungsional}

Kebutuhan Non-Fungsional dari sistem yang dibangun adalah :

a. Admin lebih bersifat sebagai pemelihara aplikasi dan melakukan pengolahan data.

b. Adanya antarmuka pengguna yang mudah digunakan.

\subsection{Perancangan}

Tahapan perancangan (design) dalam aplikasi ini meliputi rancangan arsitektur sistem, rancangan proses, rancangan basis data, rancangan struktur menu, dan rancangan antarmuka.

\section{Rancangan Arsitektur Sistem}

Dibuat untuk mengetahui bagaimana alur user mendapatkan informasi yang dibutuhkan, proses pertukaran data antara server dan client menggunakan web service, serta bersifat user friendly dan memudahkan untuk pengembangan selanjutnya.

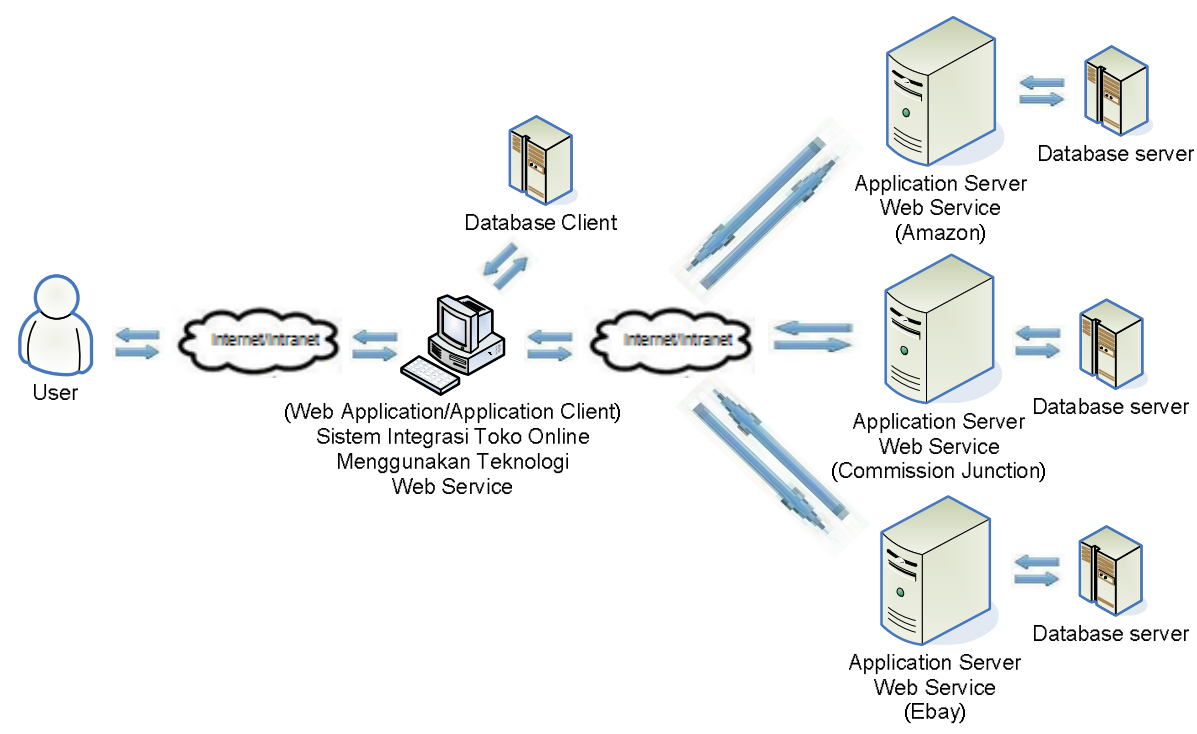

Gambar 1. Arsitektur Sistem

\section{Rancangan Proses}

Rancangan Data Flow Diagram (DFD) aplikasi ini sebagai berikut : 


\section{DFD Level 0}

Gambaran elemen seluruh aplikasi, di mana terdapat 3 user, yaitu pengunjung, admin, dan affiliate merchant (Amazon, Commision Junction, Ebay, dan Google Adsense) sebagai penyedia produk dan iklan.

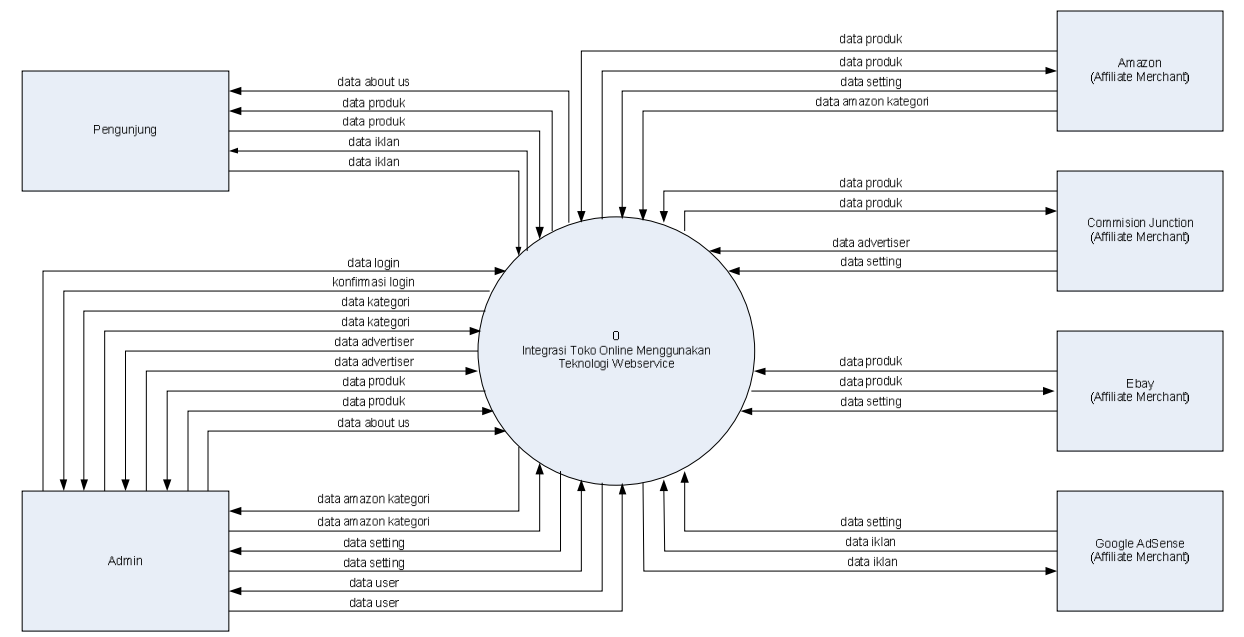

Gambar 2. DFD Level 0

\subsubsection{DFD Level 1}

Pada DFD Level 1, aplikasi penjualan online ini dapat dijabarkan menjadi 2 proses, yaitu layanan pengunjung dan layanan admin.

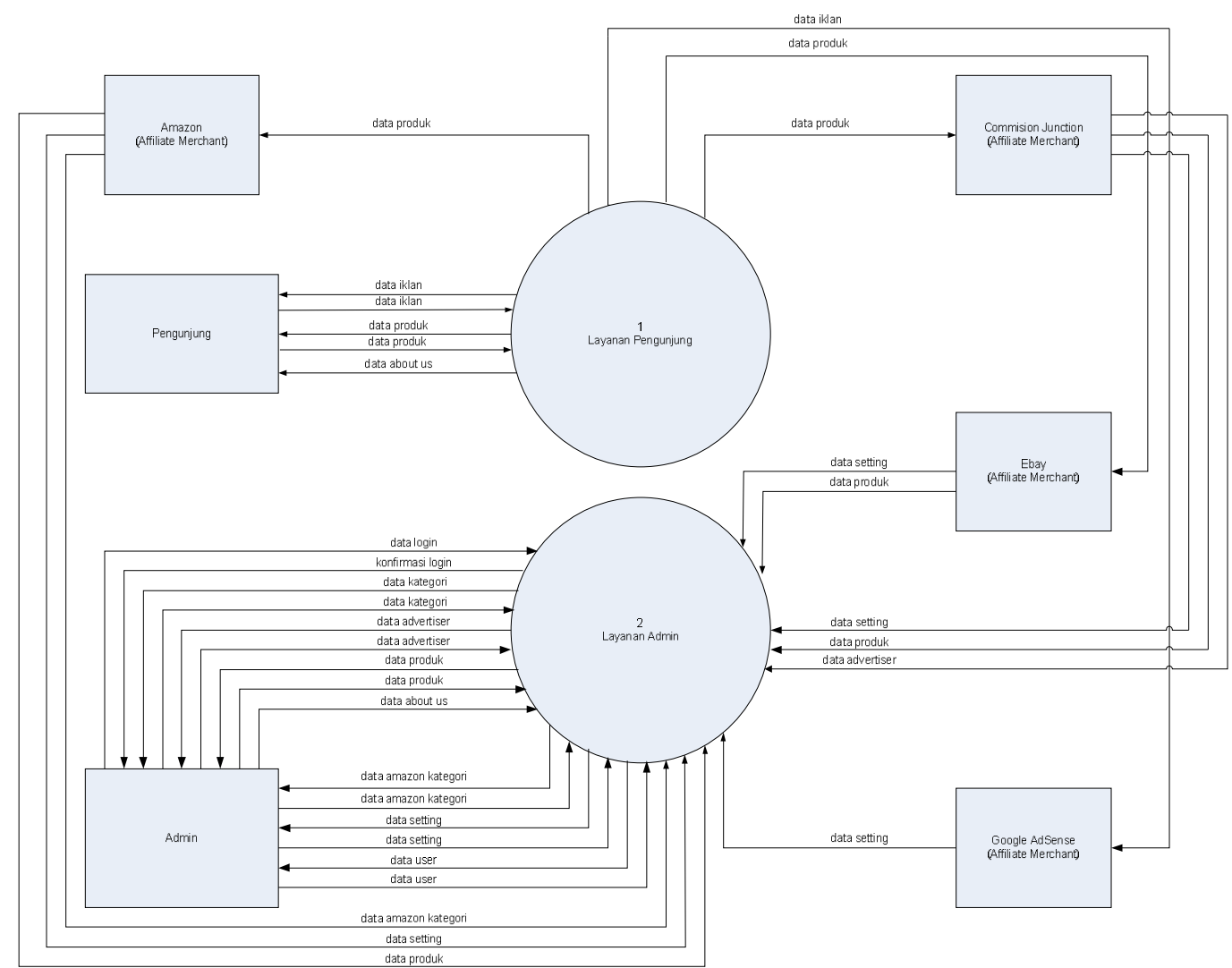

Gambar 3. DFD Level 1 


\section{Rancangan Basis Data}

Rancangan Basis data yang dibuat berorientasi objek, dengan cara melihat objek data dan disesuaikan dari penelitian data yang didapat.

\section{Entity Relationship Diagram (ERD)}

Entity Relationship Diagram (ERD) merupakan rancangan relasi antar tabel yang menunjukan hubungan integralitas.

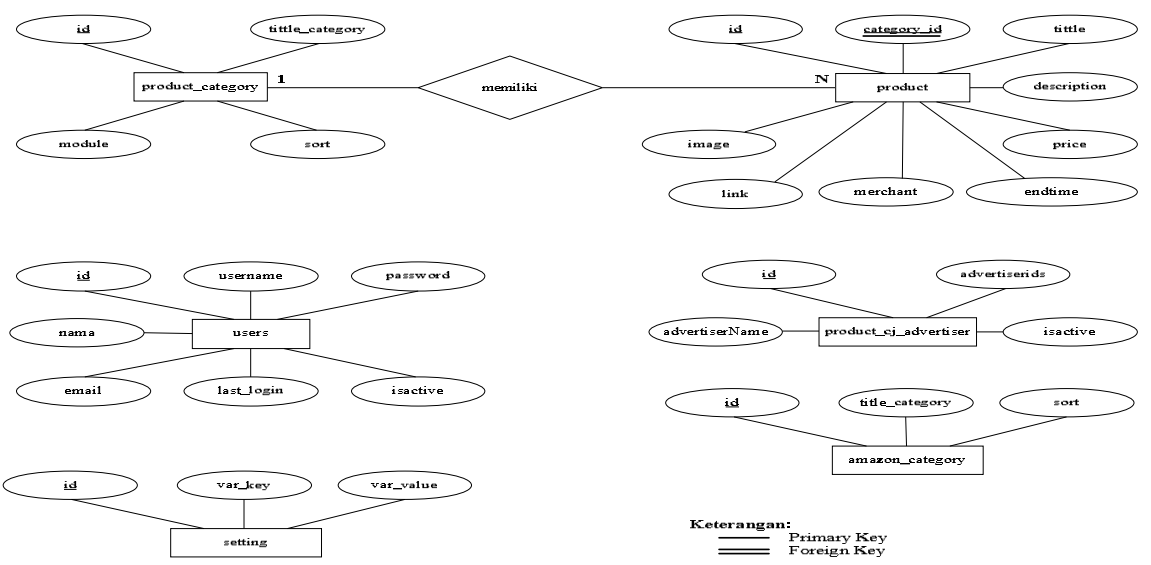

Gambar 4. ERD

\subsubsection{Hasil Perancangan}

Dari perancangan ERD (Entity Relationship Diagram), maka dapat dijabarkan tabeltabel yang diperlukan dalam sistem ini yang terdiri atas:

1. Tabel users

Tabel ini berisi field untuk menyimpan data-data admin beserta data login-nya.

Tabel 1. Tabel user

\begin{tabular}{|l|l|l|l|}
\hline Field & Tipe Data & Constrain & Keterangan \\
\hline$\underline{\text { id }}$ & int(11) & Not Null, Primary Key & ld \\
\hline username & varchar(100) & Not Null & username untuk login \\
\hline password & varchar(50) & Not Null & password untuk login \\
\hline email & varchar(100) & Null & Email \\
\hline name & varchar(100) & Null & nama asli \\
\hline last_login & datetime & Null & waktu login \\
\hline isactive & enum('1','0') & Not Null & aktif atau tidak aktif \\
\hline
\end{tabular}

2. Tabel product_category

Tabel ini berisi field untuk menyimpan data-data kategori produk.

Tabel 2. Tabe product_category

\begin{tabular}{|l|l|l|l|}
\hline Field & Tipe Data & Constrain & Keterangan \\
\hline$\underline{\text { id }}$ & int(11) & Not Null, Primary Key & id kategori \\
\hline tittle_category & varchar(200) & Null & nama kategori \\
\hline sort & int(10) & Not Null & Pengurutan \\
\hline
\end{tabular}

3. Tabel product

Tabel ini berisi field untuk menyimpan data-data produk dari affiliate merchant. 
Tabel 3. Tabel product

\begin{tabular}{|l|l|l|l|}
\hline Field & Tipe Data & Constrain & Keterangan \\
\hline$\underline{\text { id }}$ & int(11) & Not Null, Primary Key & Id \\
\hline category_id & int(10) & Not Null, Foreign Key & id kategori \\
\hline title & varchar(255) & Not Null & nama produk \\
\hline description & varchar(255) & Null & gambar produk \\
\hline image & text & Null & link produk \\
\hline price & decimal(15,0) & Null & harga produk \\
\hline link & decimal(15,0) & Null & harga eceran produk \\
\hline endtime & decimal(15,0) & Null & pabrik produk \\
\hline merchant & datetime & Null & waktu akhir produk \\
\hline
\end{tabular}

4. Tabel product_cj_advertiser

Tabel ini berisi field untuk menyimpan data-data advertiser dari store Commision Junction.

Tabel 4. Tabel product_cj_advertiser

\begin{tabular}{|l|l|l|l|}
\hline Field & Tipe Data & Constrain & Keterangan \\
\hline$\underline{\text { id }}$ & int(11) & Not Null, Primary Key & Id \\
\hline advertiserids & int(11) & Null & id advertiser \\
\hline advertiserName & varchar(50) & Null & nama advertiser \\
\hline isactive & int(1) & Not Null & aktif atau tidak aktif \\
\hline
\end{tabular}

5. Tabel setting

Tabel ini berisi field untuk menyimpan data-data id yang diperoleh dari affiliate merchant (Amazon, Commission Junction, dan Ebay).

Tabel 5. Tabel setting

\begin{tabular}{|l|l|l|l|}
\hline Field & Tipe Data & Constrain & Keterangan \\
\hline$\underline{\text { id }}$ & int(11) & Not Null, Primary Key & id \\
\hline var_key & Text & Null & merchant \\
\hline var_value & Text & Null & id dari merchant \\
\hline
\end{tabular}

6. Tabel amazon_category

Tabel ini berisi field untuk menyimpan data-data kategori untuk produk dari Amazon.

Tabel 6. Tabel amazon_category

\begin{tabular}{|l|l|l|l|}
\hline Field & Tipe Data & Constrain & Keterangan \\
\hline$\underline{\text { id }}$ & int(11) & Not Null, Primary Key & id \\
\hline title_category & varchar(200) & Null & nama kategori \\
\hline sort & int(10) & Null & pengurutan \\
\hline
\end{tabular}

\section{IMPLEMENTASI}

Pada tahap ini diketahui apakah aplikasi yang dibuat menghasilkan tujuan yang sesuai dengan analisa dan perancangan yang telah dilakukan.

Berikut adalah tampilan halaman utama pada customer/pengunjung. 


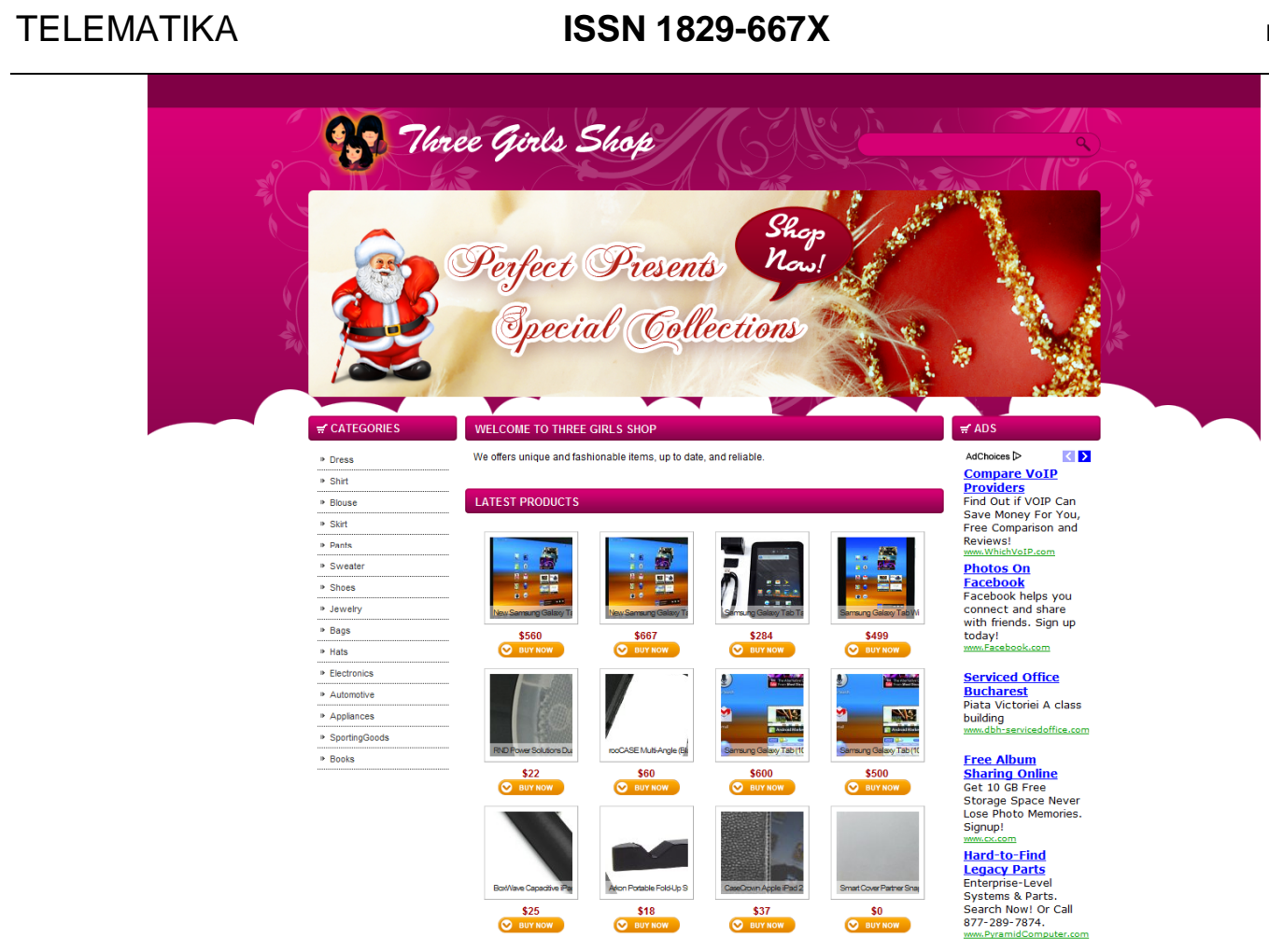

\section{True Gil Sinop 02011}

Gambar 5. Halaman utama

Berikut adalah tampilan halaman pada admin.

a. Dashboard

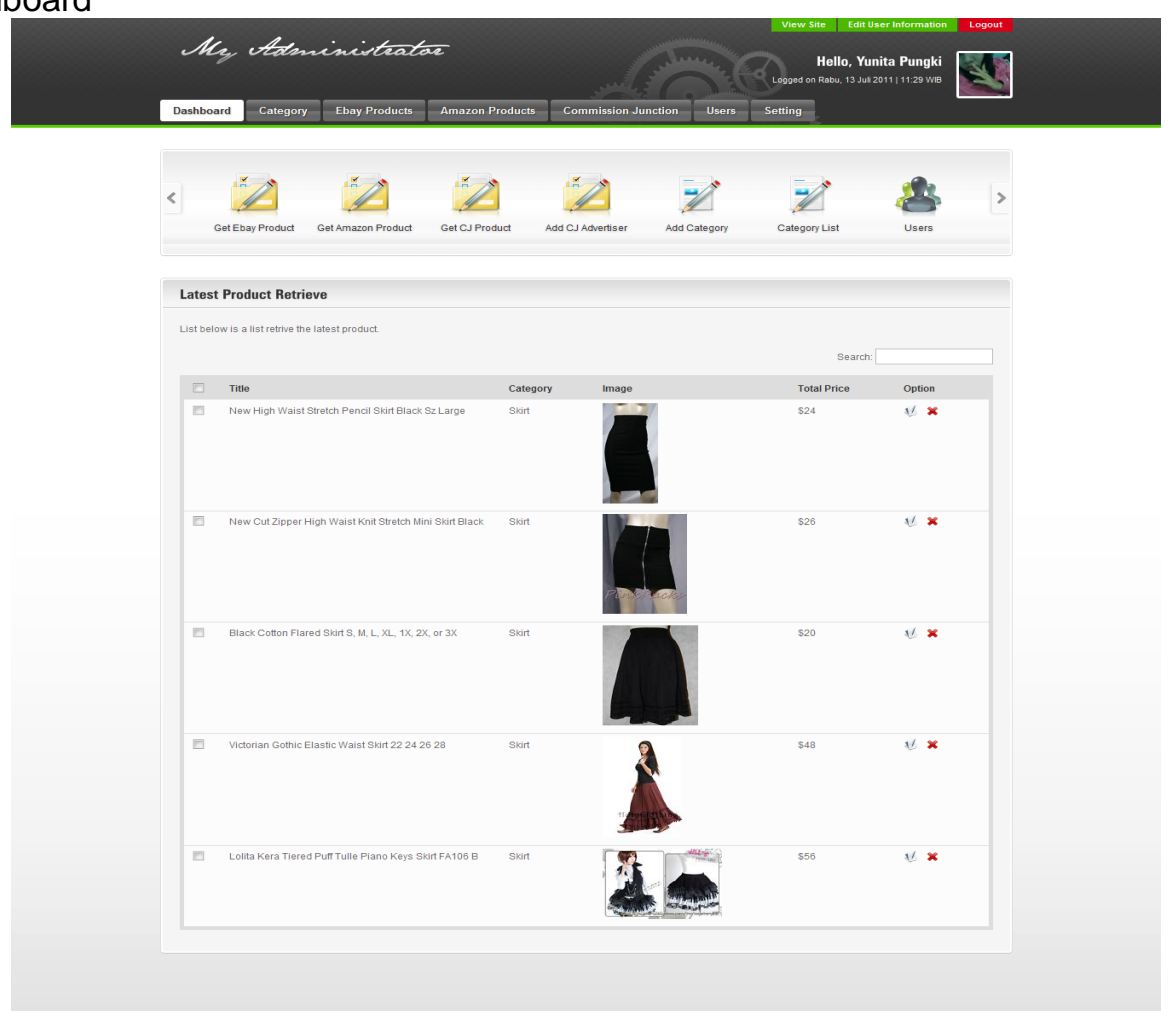

Gambar 6. Halaman dashboard 
b. Halaman Ebay Product

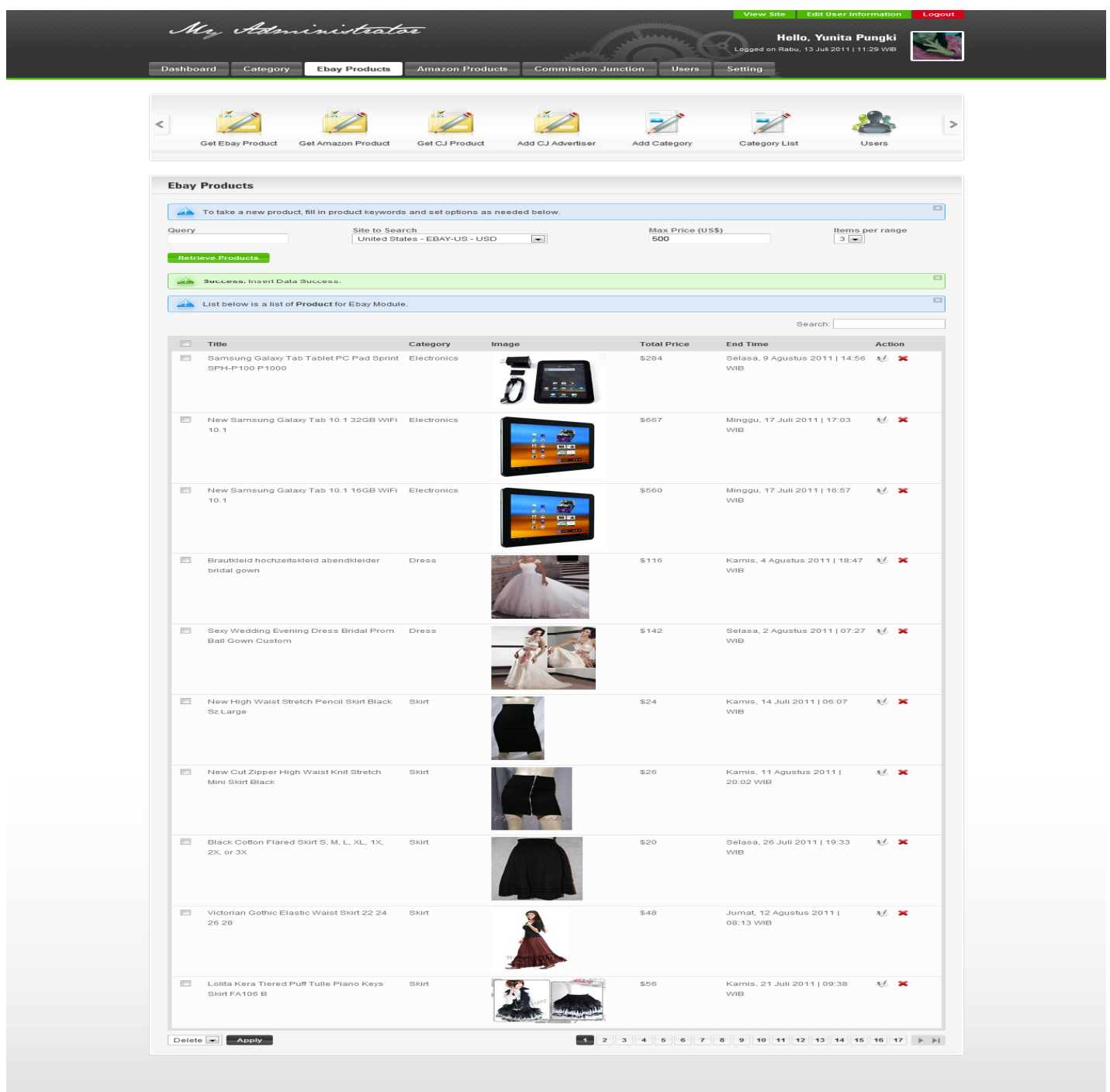

Gambar 7. Halaman ebay product 
c. Halaman Tambah Ebay Product
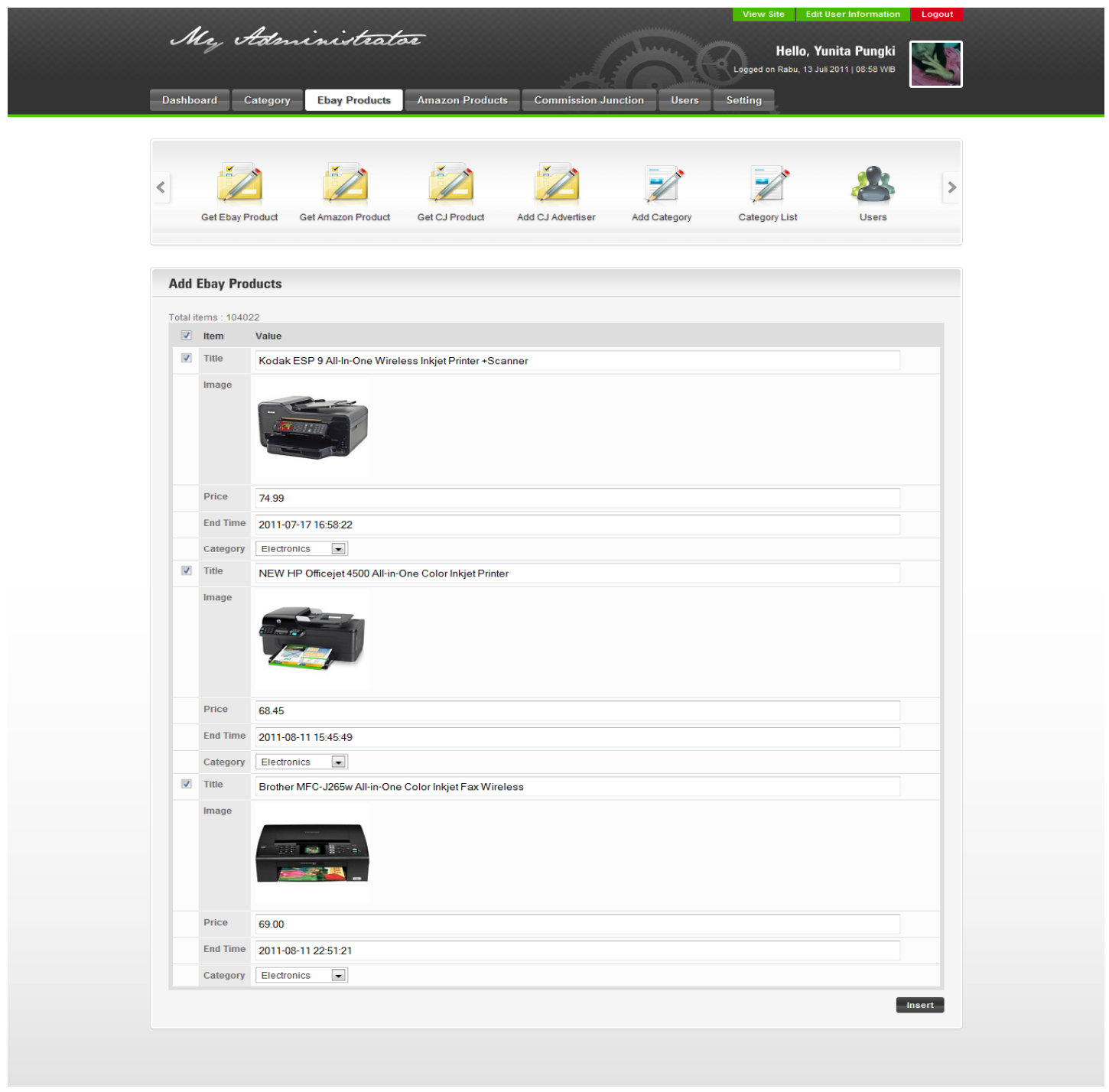

Gambar 8. Halaman tambah product

\section{KESIMPULAN}

Dari penelitian yang dilakukan telah berhasil dibangun sistem integrasi toko online dengan menggunakan teknologi webservice yang menyediakan informasi tentang produk dari beberapa affiliate merchant, yaitu Amazon, Ebay, dan Commission Junction, serta menyediakan halaman bagi admin untuk mengolah data-data produk. 


\section{DAFTAR PUSTAKA}

Achmad, Kusuma Adi, 2008, Analisis dan Perancangan istem Informasi Pelayanan Terpadu Berbasis Webservice di Pemerintah Kota Pekalongan, Program Studi MagisterTeknologi Informasi Jurusan Teknik Elektro Fakultas Teknik, Yogyakarta.

Lucky, 2008, XML Web Service: Aplikasi Desktop, Internet \& Handphone, Jasakom, Jakarta.

Madiun, Madcoms, 2009, Desain Web dengan Adobe Fireworks CS4 \& Adobe Dreamweaver CS4, Penerbit Andi, Yogyakarta.

Nugroho, B, 2004, PHP \& mySQL dengan editor Dreamweaver MX, Penerbit Andi, Yogyakarta.

Pressman, R, S, 2002, Rekayasa Perangkat Lunak, Andi, Yogyakarta.

Purbo, Onno W., 2000, Mengenal E-Commerce, PT.Elex Media Komputindo, Jakarta.

Sakti, Nufransah Wira, 2001, Perpajakan dalam E-Commerce, Belajar Dari Jepang, dalam Berita Pajak No. 1443/Tahun XXXIII/15 Mei 2001.

Sanusi, Arsyad M., 2001, E-Commerce, Hukum Dan Solusinya, PT Mizan Grafika Sarana. Jakarta.

http://blog.bukatokoonline.net/apa-itu-afiliasi (Accessed September $23^{\text {rd }} 2010$ ).

www.blog.mybcshop.com/2009/12/tentang-bisnis-afiliasi-di-internet (Accessed September $23^{\text {rd }}$ 2010).

http://www.w3c.org/TR/REC-xml (Accessed Januari 11 $1^{\text {th }}$ 2010).

http://id.wikipedia.org/wiki/Antarmuka pemrograman aplikasi (Accessed Januari 11 $1^{\text {th }}$ 2010).

http://www.ipangsan.web.id/api-application-program-interface/ (Accessed Januari 11 ${ }^{\text {th }}$ 2010).

http://id.wikipedia.org/wiki/PhpMyAdmin (Accessed Januari 11 ${ }^{\text {th }}$ 2010).

http://id.wikipedia.org/wiki/CSS (Accessed Januari 11 ${ }^{\text {th }}$ 2010).

http://www.scribd.com/doc/5041041/Tutorial-JavaScript-Indonesia (Accessed Januari $11^{\text {th }}$ 2010). 